\title{
الإنهوجرافيك الافتمرك.
}

\section{أ.د. داليا أحمد شوقى كاهل}

أستاذ تكنولوجيا التعليم

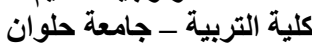

ymdalia@gmail.com

إعادة عرض النصوص والصور وتكرارها أكثر من

مرة، كما أن تقديم البيانات فى صورة لقطات فيديو

توضح خليط للمعالجات الرسومية و النصوص معا بـ أنواع الإنفوجرافيك المتحرك:

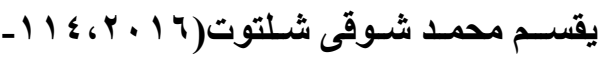

ه 11 )؛ ولمياء عبد الكريم قاسم، ولينا عاطف عبد

العزيـز مسروة، ومحمــ سـميز محمـد سـد

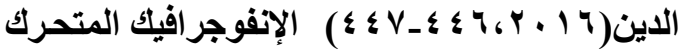
إلى أسلوبين أساسيين هما:

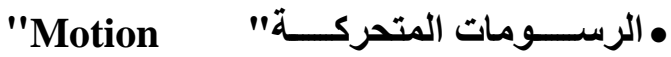
infographic و التوضيحات والمعلومات بثكل متحرك كامل، حيث يتطلب هذا النوع كثير من الإبداع واختيار الحركات المعبرة التي تسـاعد في اخراجها بطريقة شيقة وممتعة، وكنلك يكون لها سيناريو كامل للاخراج النهائي، إلا أن هذا النوع يحتاج إلى مصممين أكثر احترافيـة فى استخدام برامج التصـيم الجرافيكى المتخصصة، وقد استخدت الباحثة هذا النوع بشكل
أـ مفهوم الإنفوجرافيك المتحرك:

للإنفوجرافيك المتحرك عديـ من التعريفـات، حيث يعرفه اندري (Andrei, 2013, 4) بأنه: مزيج من المعلومات والصور يستخدم لعرض حدث ما من خلال تمثيل البيانات بصريًا. ويعرفـه بيجيـل وهانـ Hand， 2014) الجرافيكـى المشــتمل علــى الصــور و الرســومات المصـــورة، المدعمة بالنصــــوص والثــــروحات و التعليمــات فـى شـكل واحــ، لعـرض القصــص والموضوعات المختلفة. كذلك يعرفه كلُ من دالتون وديزين (Dalton \& Design, 2014, p.2 )بأنه تمثيـل بصـرى متــرك للبيانـات والمعلومسـات يـتم تصـميمه بحيـث يســـح للقـارئ باسـتيعاب وفهـم المعلومات والمعرفة بشكل واضح وسريع. ويعرف شياسـون (Dur, 2014, p.26) الإنفوجرافيك المتحرك بأنه حالة خاصة من التفاعل داخل الرسـوم تســاعد علـى المشـاهدة الواضـحة والاسـتخدام الفعـال بالتقديم والتـاخير مـع إمكانيـة

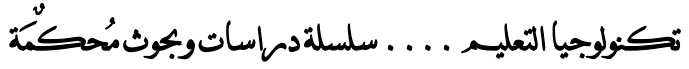


الجمعية المصرية لتكنولوجيا التعليم

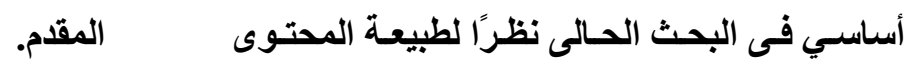

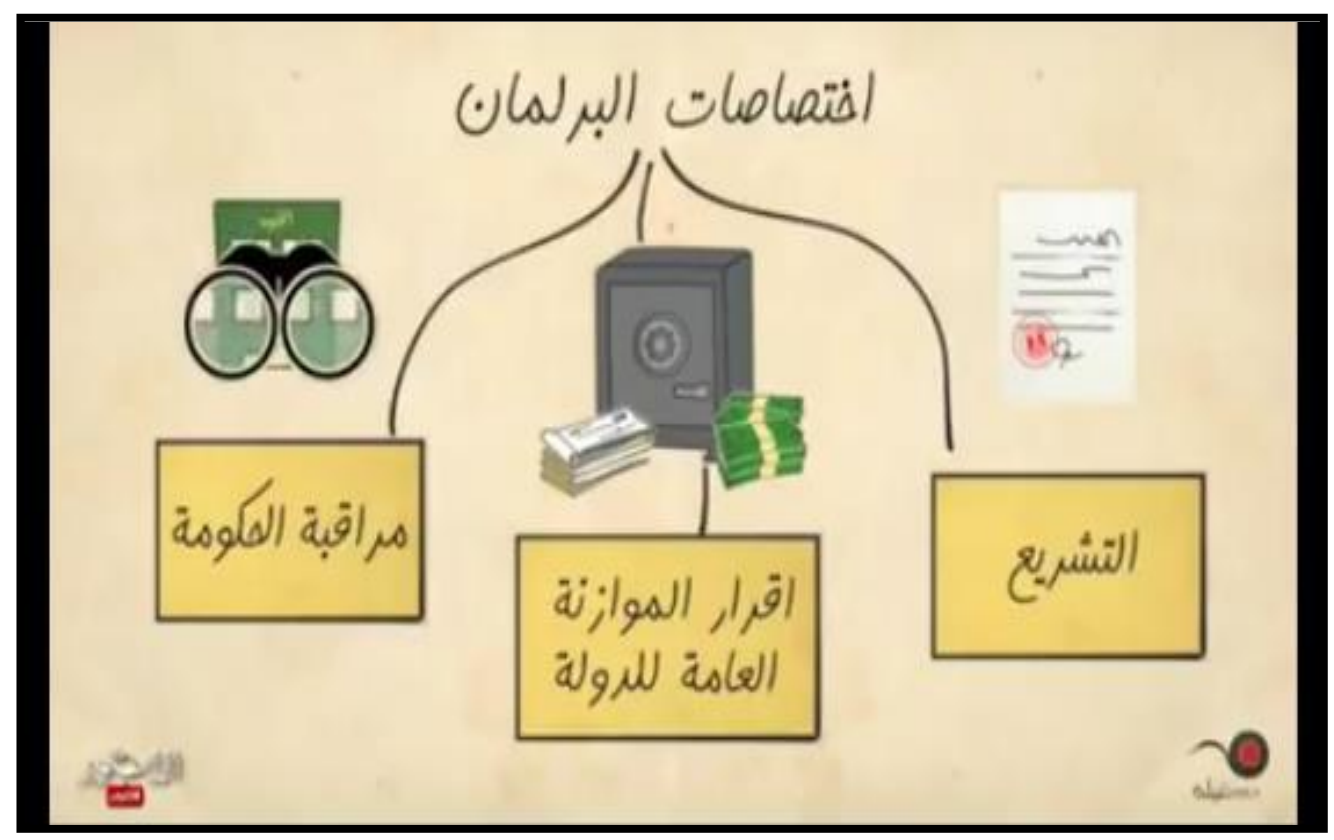

شكل (ץ) نموذج للإنفوجر افيك المتحرك القائم على الرسومات المتحركة

Video Based "لقطـات الفيـيو •

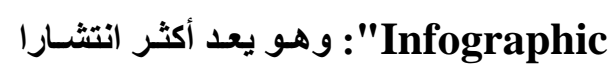
في مواقع الويب التي تستخدم تكنولوجيات

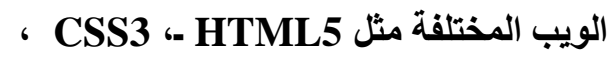
Java Script

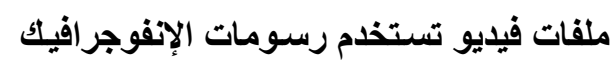
لتمثيل المعلومـات، وتشمل تصوير فيديو يوضـع عليه البيانـات و التوضيحات بشكل جرافيك متحرك لإظهار بعض الحقائق والمفاهيم علي الفيديو نفسه. 


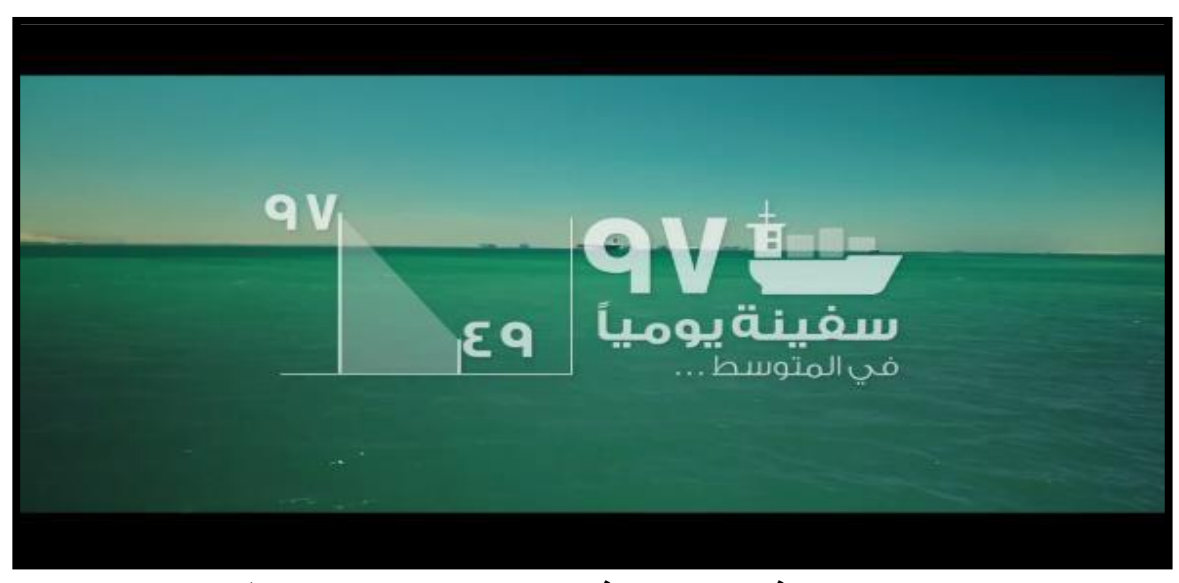

شكل (r) نموذج للإنفوجر افيك المتحرك القائم على لقطات الفيديو

دراسـة (2006) Lester) ودراسـة Begel ه H Hand (2014, 8-9)

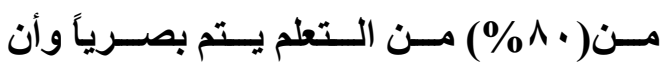

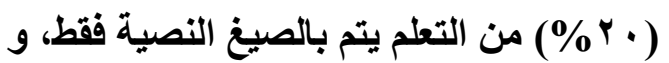

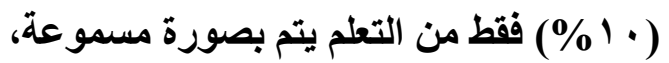

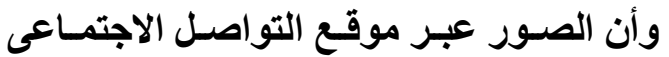

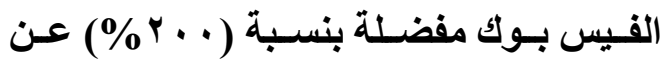
النصـوص، وأن متوســط تســيلات مواقـع

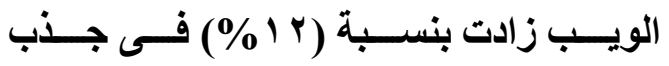
المسـتخدمين بعـد نشـر الإنفوجر افيــك، وأن العـروض التقديميـة المدعومـة بالإنفوجرافيك أقنعت V V\% \%ن المستقبلين. (Y) قابليــة تطبيقــهـه علـــى عــد كبيـر مــن التخصصــات والمجــالات المختلفــة للبيانـات (صور، أرقام، نصوص). (r)تعدد أنماط عرض الإنفوجرافيك وأساليبه. $\bullet$ ج- مميزات الإتفوجرافيك المتحرك . هناك عديد من الاراسات التى أكلدت على مدى

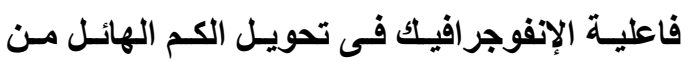

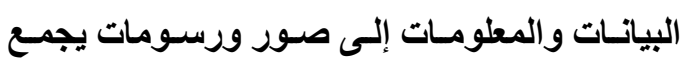

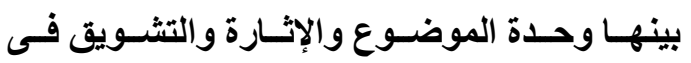

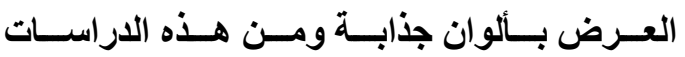
Dur,2014 ؛ Boss ,2012 ؛simiciklas, 2012 ) Lamb, Dalton \& Design, 2014 ؛

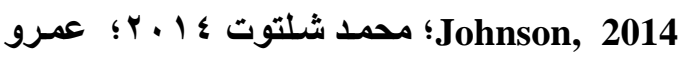
محمد درويش، أمانى أحمد الدخنى، 10 ـ بـ؛ لولوه

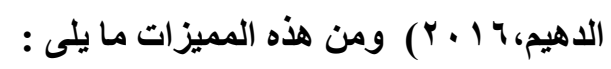
(1)سـهولة نشـر الإنفوجرافيك وانتشــاره عبر

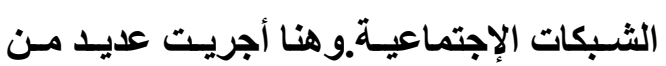
البحـوث فـى السـنوات الأخيـرة للكثـف عن الأن

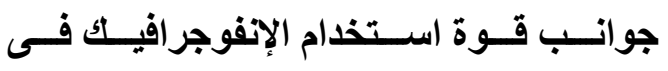

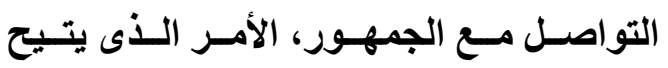
للقـائمين على العمليـة التعليميـة استثمار تلكي الجوانب فى دعم عمليتى التعليم والتعلم، فنجد تكنولوجيا التعليـم ... . سلسلةدراساتوبجوثمُحطكمة 
مقترحة قائمسة على الإنفوجر افيك في اكتسـاب

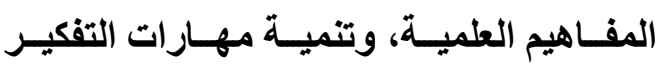
البصرى، والاستمتاع بتعلم العلوم للدى تلاميذ الصف الخامس الابتدائى، كما أوصت الارساسـة بأهميــة اســتخدام الاســتراتيجية المقترحسة القائمة على الإنفوجرافيك فى تدريس مقررات

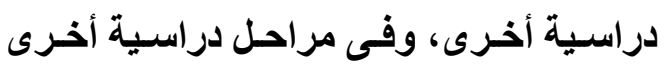
مختلفة.

(1) (1) (الإنفوجرافيك المتحرك أوسع انتشـاراً من الفيديو والكتابة، وذلك كونه يختصر كثير من الكتابـة والصـوت والصـور فى رمـوز وصسور تعبيريــة ودلالات بسـيطة، وفـى هـذا الصــد

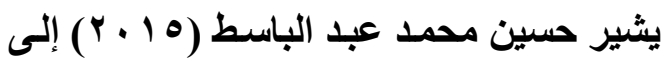
أن حوالى( • 9\%) من المعلومـات التى تنتقل إلى المـخ هـى معلومـات مصسورة، وأن حوالى هـ

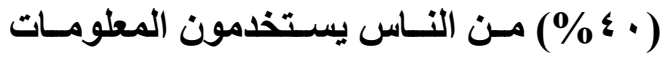
المصــورة بثـــل أفضـل مــن المعلمومــات النصية، وأن المخ يعالج المعلومـات المصورة أسرع من المعلومات النصية. (1 (1) يعـد أداة قويـة لتقـديم المعلومـات بشـكل

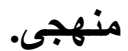
(Y Y ( ) ( ) فيكبر الصـغير ويصـغر الكبيرلإمكانيـة فهمسه ودراسته، كما أنه يسـاعد على فهم المجردات بمحتلف أنواعها.
( ) إمكاتيـة إنتاجـهـ بعديــ مـن المواصفات ممـا

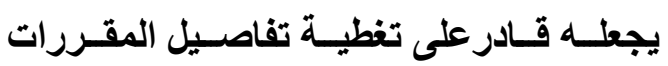
التعليمية على نطاق واسع.

(•)يقدم الحقـائق العلمية فى صورة معلومـات بصرية. (7)يعزز القدرة على التفكير وربط المعلومـات وتنظيمها. يعد طريقة فعالة لنقل المعلومـات والمعرفة (V) لأنه يبسط الأمور ويجعلها أبقى أثراً، حيث أن الصـور والرمـوز والتصـاميم الجيدة والألـوان الجذابة التى يتميز بها الانفوجرافيك بإمكانها تشجيع المتعلمين على فهم أفضل للمعلومـات المقدمة له.

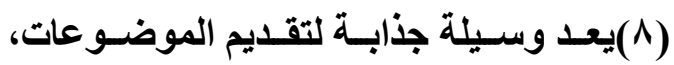
وإثـارة فضــول المتعلمسين وتنميـة مهــاراتهم

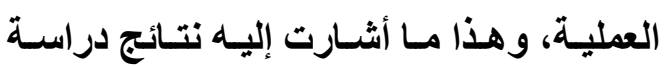

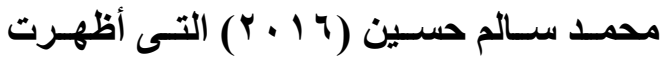

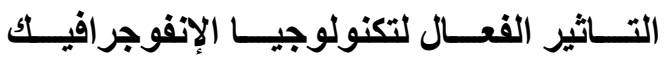
المتحرك على تعلم الأداء المهارى والتحصيل

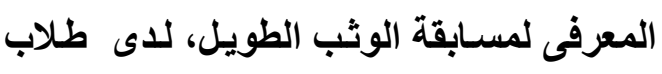
الفرقة الثالثة بكليـة التربيـة الرياضية للبنـين بجامعة حلوان. (9) (9ساعد القائمين على العملية التعليمية فى تقديم المناهج الاراسية بأسلوب جديد وشـائق وفى هذا الصدد أظهرث نتائج دراسـة عاصم محمـ إبـراهيم (7 1 • ب) فاعليـة اسـتراتيجية 
الجمعية المصرية لتكنولوجيا التعليم

تناول عديد من الدراسـات والبحوث المعايير

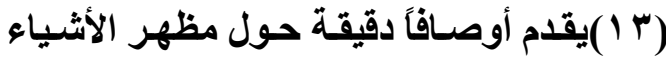

التصميمية التي مـن الواجب اتباعها عنــ تصميم

باســتعمال الأثــكال والملمـسـ والتراكيـبـ

الانفوجر افيك بصفة عامـة والانفوجرافيك المتحرك

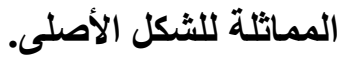

Ferreira, على وجه التحديد منها، دراسة فيريرا

(2014 )التى أشسارت إلى بعض المعايير التي من

الواجب مراعاتها عند تصميم الانفوجرافيك، وهي:

•وضــع تصـور مبـدئي للتصـميم قبـل بـدء

التنفيذ الفعلى للأنفوجرافيك ـ مبلدي

•اختيار عنوان واضـح وجذاب ومعبر عن

محتوى الأنفوجرافيك.

( ا ()يسـاعد في ترسـيخ المعلومسات وتثبيتهـا وتعميقها فى أذهان الطلاب، وهنـا تشبير نتائج

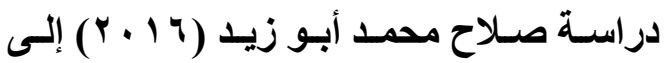
فاعليـة الإنفوجر افيـك فـى تـــريس الجغرافيـا

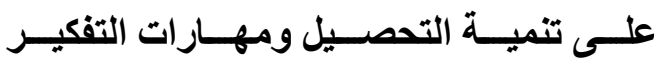
البصرى لطلاب المرحلة الثانوية. (0) (1 )يوفر الوقت والجهد على المتعلم والمعلم. •الايجـاز ومحاولـة الحد من كثرة البياتـات (7 ( ) يستثير دافعية الطلاب ويحفزهم على تعلم

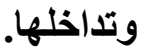

•التـوع في اسـتخدام التصـميمات لإيصـال

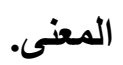

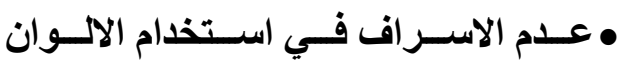

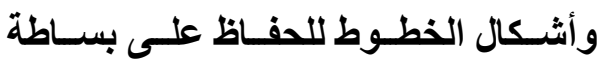

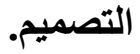

•اسـتخدام البيانـات ذات الصـلة بموضـوع الإنفوجرافيك.

كذلك حدد مصطفى جودت (10 ب ץ) المعايير التي من الواجب إتباعها عند تصميم الإنفوجرافيك

•التركيز على فكرة واحـدة عنـــ تصـيم الإنفوجرافيك. المحتوى المقدم.

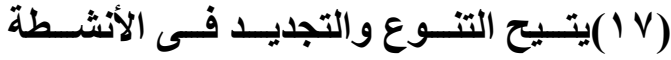
المقدمة، مما يسهم في علاج الفروق الفرديـة

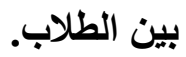

(1 ( ) ينمى دقة الملاحظة وروح النقد ويسـاعد على تدريب حواس الطلاب وتنثيطها

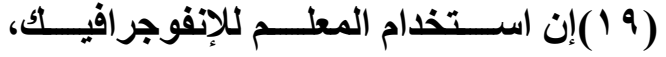
وتبسيط شروح دروسـه من خلاله يقربـه من الطلاب ويحببـه لهم ممـا يؤدى لزيـادة ثقتهم به، ويزيا إقبالهم على المادة.

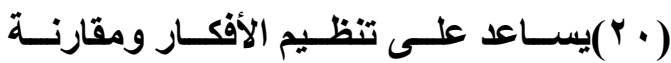
المعلومات بطريقة فعالة ومثيرة. دـ معايير تصميم الانفوجرافيك المتحرك: 


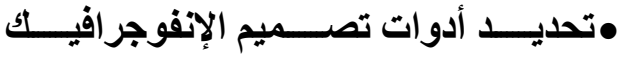

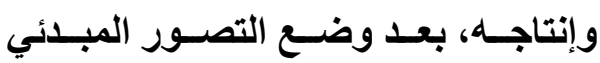

لتصـيم الانفوجر افيك، يتم اختيـار انسب وصب

البرامج والتكنولوجيـات اللازمـة لتصـميم

الانفوجرافيك.

كنلك قام يلدريم (Yildirim, 2016) بتحيد

مجموعـة مـن المعـايير عنــ تصـميم الانفوجرافيــ

$$
\text { التعليمي، هى: }
$$

•تحديد الهوف من تصميم الإنفوجرافيك.

•كتابـــة عنــــوان واضــــح يعبــر عــن

$$
\text { الإنفوجر افيك ويميزه. }
$$

•تــوفير الاتســاق بـين المعلومــات التــي يتضمنها الإنفوجرافيك.

•التخطيط البصري الجيد للمعلومـات التي

$$
\text { يتضمنها الإنفوجرافيك. }
$$

•تقديم معلومات صحيحة وغير مغلوطة. •مراعـاة الهـف من الإنفوجرافيك في كل لـ

$$
\text { مرحلة من مراحل تصميمه. }
$$

•معلومية الشخص أو المؤسسة التي قامت

$$
\text { بتصميمه. }
$$

•ألا يقــدم الإنفوجرافيـك معلومـات أكثر أو أقل مما هو مطلوب للمهمة قيد التعلم.

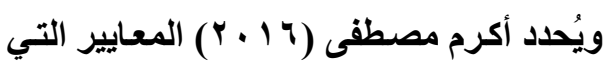

من الواجب الالتزام بها عند تصميم الإنفوجرافيك

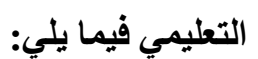

•التركيـز عـى المركـز البصــري للعمـل؛

بحيث تتبع الفكرة من المنتصف، لتسـهيل قراءة الإنفوجر افيك. • عرض البيانات بدقة ووضوح. •المحافظة على جمـال التصميم مـن خـلال

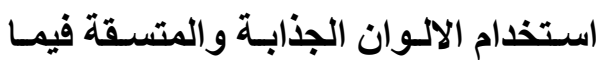

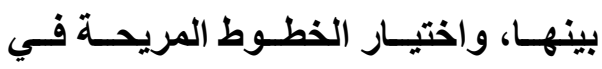
القراءة، والاستغلال الجيد للظل والضوء.

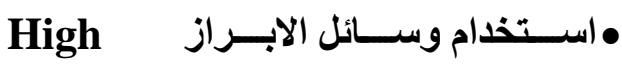
Lighting بشكل يسـاعد المستخدم على

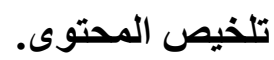

ووضع كل من حمـاده محمد مسعود، إبراهيم يوسف محمد (10 ب م ب) عدد من المعايير التي من

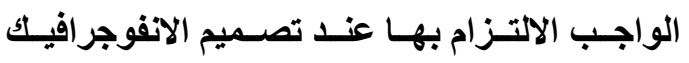

$$
\text { التعليمي، هي: }
$$

•اختيار موضوع الانفوجرافيك، كلمـا كانت

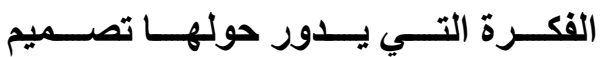
الانفوجرافيك مختـارة بعنايـة، كلمـا سـاعد ذلك على نجاح الانفوجرافيك. •جمع عناصر التصميم، حيث يتوقف نجـاح الانفوجر افيك على مدى صدق المعلومـات

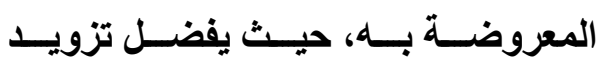
التصـميم باحصـائيات ورسـومـات بياتيـة تدعم فكرة الإنفوجرافيك موضع التصميم. •التخطيط، يحتاج الإنفوجرافيك إلى تخطيط جيد قبل البدء في تنفيذه.

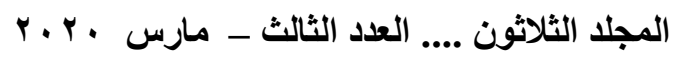


الجمعية المصرية لتكنولوجيا التعليم

•أن يكون الإنفوجر افيك خالي من الأخطاء

$$
\text { الاملائية والنحوية. }
$$

وقد قامـت الباحثة في البحث الحسالي بتقديم

محتوى التعلم المقدم لطلاب الدبلوم العام باستخدام

الإنفوجر افيـك المتحرك وفـق عـدـ مـن المعـيير

التصميمية التي حددتها الباحثة في ملحق (ץ)، وقد الإند

أشتملت هذه المعـيير على ثمانيـة معـايير رئيسـة،

$$
\text { تضمنت (7 (7) مؤشرًا. }
$$

هـ البرامج الملائمة لانتاج الانفوجرافيك

$$
\text { المتحرك: }
$$

يوجد عديد من البرامج المستخدمة فى إنتاج

الفيديوهات القائمة على الرسومات المتحركة ومنها

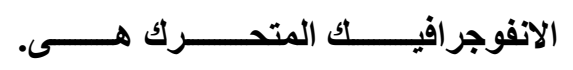

(https://www.amnaymag.com)

Adobe After أـوبي أفتر إفكتس Effects ورسومات متحركة من شركة أدوبي، يُستخدم في تحرير الفيديو وصناعة المؤثرات البصرية والفواصل المتحركة المستخدمة في البرامج والإعلانات التلفزيونية بالإضافة إلى استخدامه في مرحلة ما بعد الإنتاج السينمائي

$$
\text { والتلفزيوني. }
$$

ويتميـز برنــامج أدوبــي أفتـر إفـــس بأنــهـ برنامج يعتمد على نظام الطبقات في التحرير، فلكل عنصر (صورة، فيديو، صوت) طبقة خاصة به تتيح للمستخدم التعديل عليها بشكل منفرد، كمـا أنها يتيح
•معايير تربويـة: وتثـمل المعايير الخاصـة بصسياغة الاهــاف والمحتـوى ومناسـبته لخصائص المتعلمين وبيئة التعلم. •معــايير تكنولوجيـة: وتثـــل المعـايير المرتبطة بتصميم المثيرات وتفاعلها مـع

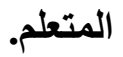

•معاييز عامة: وتثـل المعايير التي يجب توافرها في الانفوجرافيك بشكل عام.

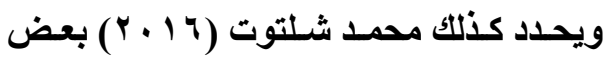
المعايير التي من الواجب الالتزام بها عند تصميم الإنفوجر افيك التعليمي،هي:

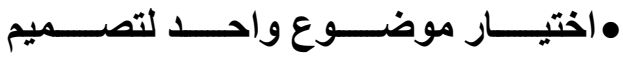
الإنفوجرافيــك ، حتـــي يكــون ذا تركيـز

$$
\text { ووضوح. }
$$

•اختيار عنوان معبر ومميز للانفوجرافيك. •اختيـار بيانـات ومعلومـات يمكن تمثيلهـا بصريًا. •أن تتســـم المعلومـــات التـــي يتضـــــهـا الإنفوجر افيك بالصحة والموثوقية. •أن يتسـم تصـيم الإنفوجرافيك بالتسلسـل في عرض المعلومات. •أن يتم اختيـار الرمـوز والأشكال التعبيريـة التي يتضمنها الانفوجرافيك بعناية. •أن تكون الألوان جذابة ومتناسبة مع فكرة وهدف الانفوجرافيك.

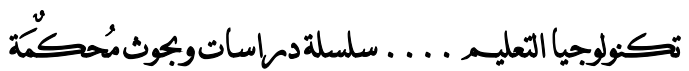


12وهو يتضمن كل المميزات التى تقدها عادة البرامج المتخصصة في هذا المجال وهو يأتي بثكل افتراضي مع اصدارات ويندوز باستثناء 1. ويندوز د-برنامج"LightWorks" يعد من البرامج الإحترافية في هذا المجال وهو يتوفر بنسختين الأولى مجانية وهي التي تخرج بفيديوهات بدقة

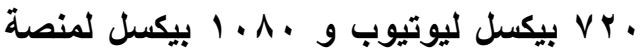
"Vimeo" أما النسخة المدفوعة تقدم فيديوهات بدقة أعلى تصل حتى ؛.k، ويقدم هذا البرنامج مزيد من الاعدادات والخصائص المتقدمة لتخصيص الفيديوهات وتطويرها والخروج بأفضل جودة ممكنة. ه- برنامج VideoPad Editor يتيح البرنامج إنثاء مقاطع الفيديو وإنتاجها من خلال دمج أكثر من مقطع فيديو للحصول علي فيلم من إنشائك، بالاضافة إلي ذلك يتيح البرنامج إمكانية إضافة التأثيرات علي الفيديو وإضافة الفواصل والإنتقالات بين كل فيديو أوشريحة تستخدمها في إنتاج الفيديو، وكذلك يتيح البرنامج الكتابة علي مقاطع الفيديو مع إمكانية تغيير الخط واللون ومكان ظهور الكتابة علي الثاثة، يمكن أيضا دمج صوت معين علي الفيديو مع إمكانية إضافة تأثيرات صوتية رائعة عليه من خلال المكتبة المتوفرة في البرنامج. يوفر إمكانية إضافة الصور أيضاً داخل الفيديو .
للمستخدم تحرير، وتحريك، ودمج العناصر والمواد الفنيـة في المحيط ثنـائي وثثلاثـي الأبعاد.وبرنـامج أدوبـي أفتر أفكت بـه عديـا مـن المميزات القويـة،

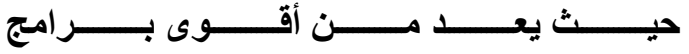
التكـوين "composition" وبـرامج التكـوين تختلف عـن بـرامج المونتــاج مثُل ادويسي بريمير ثै فا،

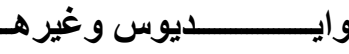
برنامج ادوبي فوتوشـوب يمكنه قص اي جزء من صورة ومسحه وتخفيف حواف القص، تقريبا يقوم برنامج أفتر أفكتس بنفس العـل مـع الفيديو، وقد قامـت الباحثة باسـتخدام هـذا البرنـامج فـى انتـاج مقـاطع الانفوجرافيـك المتـــرك بأسـاليب الانتقـال

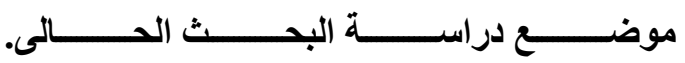

http://keefwiki.com/art/adobe-after/effects ب- برنامجiMovie : وهذا البرنامج هو من انتاج شركة آبل ماكنتوش وهو يتيح لمستخدمي أجهزتها إنتاج فيديوهات عالية الجودة يمكن أن تصل دقتها حتى إلى ؛. و ويمكتلك بسهولة من خلاله عمل الكليبات والفيديوهات المختلفة والتعديل عليها باستخدام التأثيرات، وهو يأتي بشكل مجاني مع أجهزة آبل.

ج- برنامج "'"وهو من تصميم وتطوير شركة مايكروسوفت، ويتميز بواجهة برمجية بسيطة وقد تم تحسين كثيرًا من وظائفه خصوصًا في

Windows Movie Maker الاصدار الأحدث 
الجمعية المصرية لتكنولوجيا التعليم

مختلفة، كنلك يتمتع البرنامج بإمكانية التحكم في طريقة العرض للقيديو، وتقليل/ زيادة سرعة الصور والرموز داخل المقطع، كذلك حفظ المقطع بعد الإنتهاء بصيغ مختلفة منها صيغة الباور بوينت كما يتيح نشر الفيديو على أشهر مواقع التواصل الإجتماعي كالفيسبوك ويوتيوب. jttps://WWW. ) Animoto, برنامج (animoto.com يستخلم فى عمل ملفات فيديو ذات جودة عالية من لقطات الفيديو والصور ويتيح تخزين الملفات وتبادلها عبر التخزين السحابى ومتوافق مع أغلب انظمة

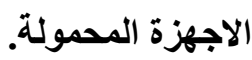

و- برنامج هideoScribe لهو برنامج من إنتاج Sparkol وظيفته تصميم مقاطع الفيديو وتطويرها بحيث تظهر بثكل متحرك عن طريق الكتابة باليد أو باستخدام بعض الأثكال الأخرى مع إضافة بعض المؤثرات والتعديل عليها لإنتاج فيديو مصمم بلرجة عالية من الإحتراف ويتم استخدامه غالباً في إنتاج مقاطع الفيديو التعليمية وله إستخدامات عدة هى: صناعة مقدمة intro أو نهاية outro للفيديو بثكل احترافي جدًا، كذللك يحتوي البرنامج على عديد من الأشكال و الرسومات المتحركة(الإيموشن) التي يمكن إضافتها مجاناً كما يمكنك من استيراد صور من حاسويك ورفعها للبرنامج بصيغ 


\section{المراجع}

أكرم فتحي مصطفى (7 ( Y) مسنويات كثافة المثير ات في الانفوجر افيك التفاعلي عبر التدوين المصغر و علاقتها بكثافة المشـاركات وتتميـة مهار ات التفكير البصري وتطوير كائنسات التعلم البصرية

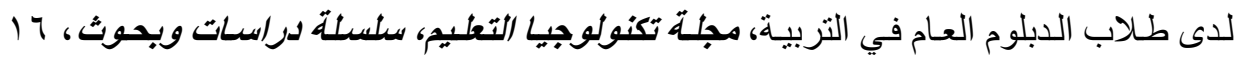

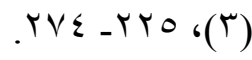

أمل حسان السيد حسن (T 1 ب أثر اختلاف أنماط التصميم المعلوماتى (الانفوجر افيك) على التحصيل وبقاء أثر التعلم لدى التلاميذ ذوى صعوبات التعلم الجغر افيا بالمرحلة الإعدادية و اتجاههم نحو المادة، رسالة ماجستبر، كلية التربية النوعية ـ جامعة عين شمس. أمل شعبان أحمد (T 1 • Y) أنماط الإنفوجر افيك التعليمى " الثابت/ المتحرك /التفاعلى " و أثره فى التحصيل وكفاءة تعلم الرياضيات لدى تلاميذ المرحلة الابتدائية ذوى الإعاقة الذهنية

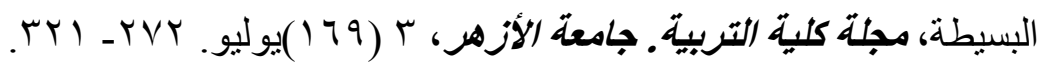

حسين محمد عبد الباسط أحمد (0 ( ب). المرتكزات الأساسية لتفعيل الانفوجر افيك فى عملتى التعليم

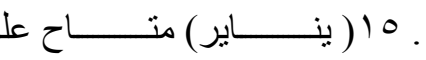
م الإلكترونـ لتعلة التعل وال

http://emag.mans.edu.eg/index.php?page=news\&task=show\&id=233

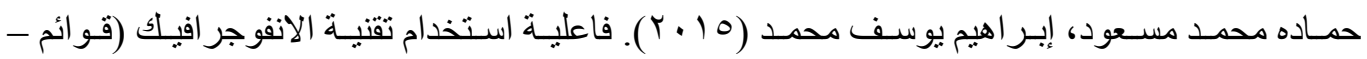
علاقات) في تتمية مهار ات تصميم البصريات لدى طلاب التربيـة الفنية المستقلين و المعتمدين

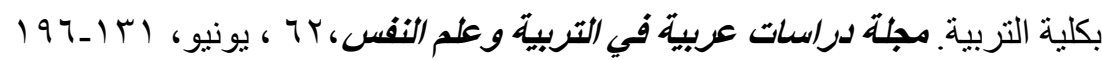
سلوى فتحى محمود المصرى (10 ب ب)أثر اختلاف نمط عرض الإنفوجر افيك كمنظم تمهيدى رسومى على تتمية مهارت رسم خرائط التدفق والتفكير المنطقى بمادة الحاسب الآلى التى

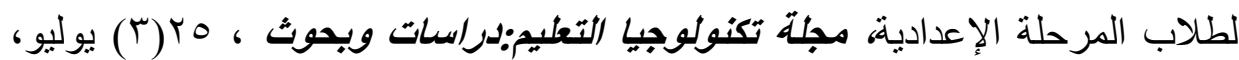

$$
.1 \leqslant 7-19
$$

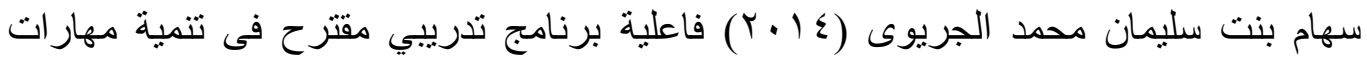
تصميم الخرائط الذهنية الإلكترونية من خلال تقنية الإنفوجر افيك ومهارات الثقافة

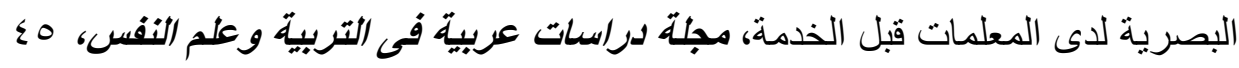
$. \Sigma V_{-} \mid r_{6}(\varepsilon)$ 
الجمعية المصرية لتكنولوجيا التعليم

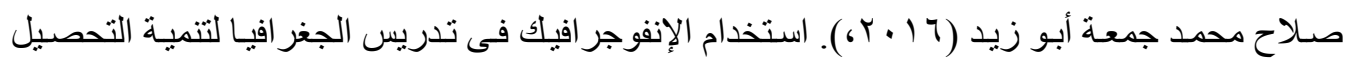

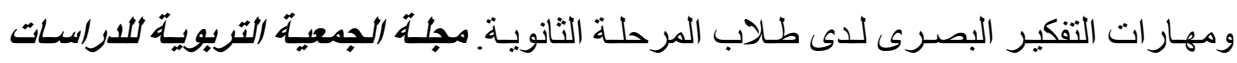

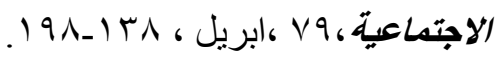

عاصم محمد إبر اهيم (T 1 ب Y) فاعلية استر اتيجية مقترحة قائمة على الانفوجر افيك فى اكتساب لمفاهيم العلمية وتتمية مهار ات التفكير البصرى والاستمتاع بتعلم العلوم لدى تلاميذ

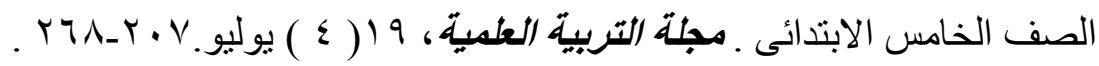

عمرو محمد درويش، أمانى أحمد الدخنى (10 ب ب) نمط تقديم الإنفوجر افيك الثابت/ المتحرك عبر

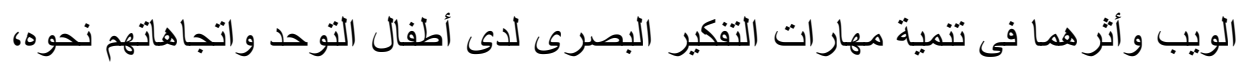

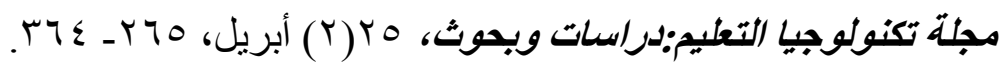

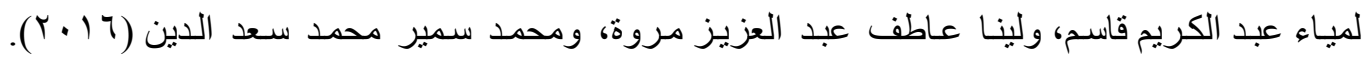

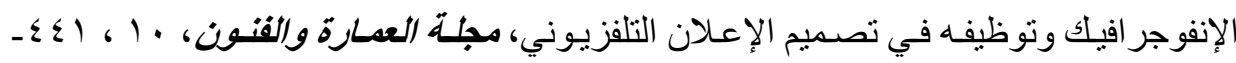
. $0 \mathrm{~V}$

لولوة الدهيم (T 1 • Y). أثر دمج الإنفوجر افيك فى الرياضيات على تحصيل طالبات الصف الثانى المتوسط

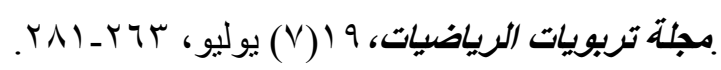

ماريان ميلاد منصور (10 ب ب) أثر استخدام تقنية الانفوجر افيك القائم على نموذج أبعاد التعلم

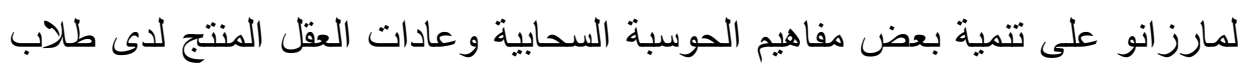

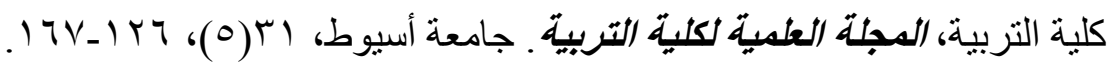

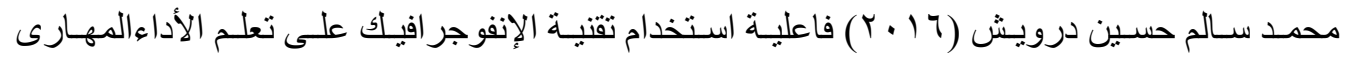

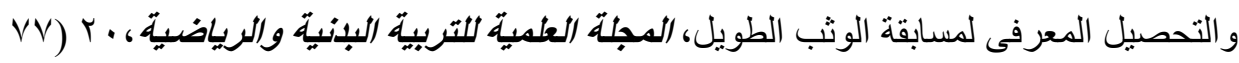

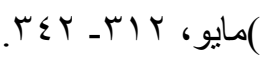
محمد سالم حسين درويش (7 ( • ؟،)فاعلية استخدام تقنية الإنفوجر افيك على تعلم الأداءالمهارى

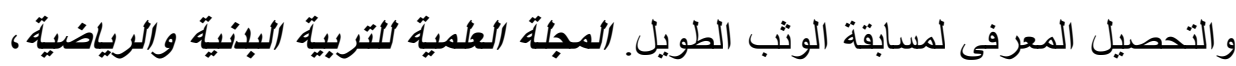

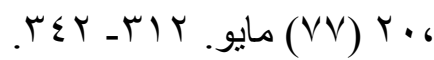




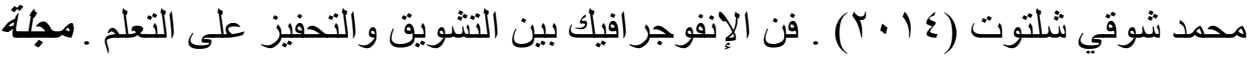

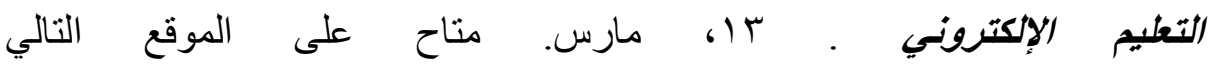

http://emag.mans.edu.eg/index.php?page=news\&task=show\&id=23

محمد شوقي شلتوت (T 1 • ب) الإنفوجرافيك من التخطيط إلى الإنتاج. الرياض، مكتبة الملك فهد

$$
\text { الوطنية. }
$$

مصطفى جودت (10 ب r) الانفوجر افيك: بين إثـكالية التعريف ومبـادئ التصميم، تم استرجاعه في

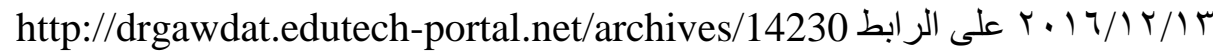

Andrei,k (2013) Infographics for outreach, Advocacy, and marketing : from Data to

Design .Ideal Ware .https://www.idealware.org/reports/infographics-outreachadvocacy-marketing-data-design

Beegel, J \& Hand ,K.(2014).Infographics for Dummies,John willey \& Sons ,Inc, New Jersey.

Dalton,J \& Design,w. (2014) Abrief Guide to producing compelling infographics, London, School of Publich Relation(LSPR) .

Davidson. R .m. (2014 )using infographis in the science classroom, journal science Development and Evaluation of a virtual Chemistry Laboratory, $\quad$ UniServe Science Improving Learning outcomes Symposium Proceeding, Charles Available from : Sturt University, $90-95$

Davis, M., \& Quinn, D. (2013). Visualizing Text: The New Literacy of Infographics. Reading Today, 31(3), pp 16-19.

http: //Download.springer.com.ugrade1.eul.edu.eg:2048/ static/ pdf.

Dur, B (2014) Interactive Infographic on the Internet, Online Journal of Art and Design , 2( 4), 103-117 
الجمعية المصرية لتكنولوجيا التعليم

Ferreira, J. (2014) Infographics: An Introduction, Center for Business in Society, Conventry University.

Krauss, J.(Feb,2012). Infographics: More than words can say, Journal Learning \&Leading with Technology,(39) 5, 10-14 .available from : $\quad$ http:// www.cityis.com/assets/downloads/emergingvalueofvirtuallabs.pdf

Lamb, A \& Johnson ,L.(2014) info graphic part1 : invitations to inquiry .Teacher librarian ,41(4), 54-58.

Lankow, J., Ritchie, J\& Crooks, R. (2012). The Power of Infographics: Visual Storytelling. John Wiley \& Sons, Inc., New Jersey.

Sekar,N .(2017). Infographic : Not Just aBeautiful Visualisation, London, .University of Birmingham .

Smiciklas, M. (2012): The power of info-graphics. Using pictures to communicate and connect with your audienes. Library of congress united states of America

Vanichvasin,p.(2013).Enhancing the quality of learning through the use infographic $\mathrm{s}$ as visual communication tool and learning tool .In proceedings : ICQA2013 Internation conference on QA culture: cooperation or competition Tung phayathai, Ratchathewi, Bangkok. Indianapolis, Indiana 46040 USA. (p.p135-142)

Y1ldırım, S. (2016) Infographics for Educational Purposes: Their Structure, Properties and Reader Approaches, The Turkish Online Journal of Educational Technology, 15 ( 3), July, 98-110

Zacks, J. \& Magliano, J. (2010), Film, Narrative and cognitive NeuroScience, Retrieved June 13, 2016 from http://dcl.wustl.edu/pdfs/zacks Maliana In Press. Pdf. 
Zettl , H (1998) "Contextual Media Aesthetics as The Basis for Media Literacy", Journal of Communication , 48 ( 1), 81-95 . 